\title{
PÓS-COLHEITA DE PÊSSEgOS (Prunus pérsica L. Bastsch) REVESTIDOS COM FILMES A BASE DE AMIDO COMO ALTERNATIVA À CERA COMERCIAL ${ }^{1}$
}

\author{
Marcelo Alvares de OLIVEIRA ${ }^{2, *}$, Marney Pascoli CEREDA ${ }^{3}$
}

\begin{abstract}
RESUMO
O presente trabalho objetivou prolongar a conservação pós-colheita de pêssegos, armazenando-os à temperatura ambiente. Inicialmente selecionou-se uma microemulsão à base de fécula de mandioca e cera de abelha. Posteriormente ela foi testada, aplicando-a na superficie dos frutos em comparação com "Fruit wax" (cera comercial), com o intuito de se verificar o efeito dos diferentes tratamentos na composição química, fisica e fisico-química dos mesmos. Utilizaram-se pêssegos 'Biuti' colhidos manualmente em 14/01/1999, ao atingirem o ponto de maturação fisiológica. Do lote colhido foram selecionados 120 frutos sendo os mesmos analisados quanto a perda de massa fresca, taxa respiratória, textura, sólidos solúveis totais, acidez total titulável e pH, a cada 3 dias. Os frutos receberam os tratamentos: Testemunha, "Fruit Wax", Fécula e Microemulsão. Os tratamentos "Fruit Wax" e "Microemulsão" proporcionaram melhor eficiência em relação à perda de massa fresca que os frutos dos tratamentos Testemunha e Fécula. Quanto à taxa de respiração, verificou-se picos da ordem de $40 \mathrm{mg}$ de $\mathrm{CO}_{2} \cdot \mathrm{kg}^{-1} \cdot \mathrm{h}^{-1}$. Quanto aos açúcares, verificou-se que a sacarose foi o açúcar encontrado em maior quantidade, com apenas traços de glicose e frutose em algumas amostras. Quanto aos teores de sólidos solúveis totais, os frutos tratados com "Fruit Wax" apresentaram valores inferiores aos do tratamento Testemunha. O efeito da Microemulsão mostrou-se similar ao da cera "Fruit Wax" em todos os atributos e, superior ao dos tratamentos Testemunha e Fécula na redução da perda de massa fresca. Palavras-chave: pêssego; armazenamento; cera; fécula de mandioca.
\end{abstract}

\section{SUMMARY}

POSTHARVEST OF PEACHES (Prunus persica L. Bastsch) COVERED WITH FILM-FORMING OF CASSAVA STARCH AS ALTERNATIVE TO THE COMMERCIAL WAX. The main objective of this work was to prolong the shelf life of peaches at ambient conditions. Initially, the studies were to get a film forming of cassava starch and bee wax with similar properties of commercial waxes. The second pass was apply in the surface of the fruits, commercial wax (" Fruit wax") or film-forming of cassava starch and bee wax. The peaches of the variety 'Biuti' were picked in 14/01/1999 and 120 uniform fruits were scratched. The analyses were of loss of fresh mass, respiration, texture, total soluble solids (TSS), total acidity, and pH tested every 3 days during 12 days. At first, fruits were put into $0.3 \mathrm{~g} / 1$ of "Benomyl" in hot water $\left(52^{\circ} \mathrm{C}\right)$ during 2 minutes. Four treatments were made: Control, Fruit Wax, Film-forming of Cassava Starch and Film forming of Cassava Starch and Bee Wax. The fruits treated Fruit Wax and Film forming of Cassava Starch and Bee Wax showed improved efficiency in relation to loss of fresh mass to the Control and Film forming of Cassava Starch treatments. The respiration was measured to be in the order of $40 \mathrm{mg} \mathrm{de} \mathrm{CO}_{2} \cdot \mathrm{kg}^{-1} \cdot \mathrm{h}^{-1}$. Sugar profile verified that sucrose is a sugar found in larger quantities, and verified traces of glucose and fructose in some samples. Equally to total soluble solids, the Fruit Wax treatment decreased the values of sucrose compared with the Control. The use of Film forming of Cassava Starch and Bee Wax was better than the expectations, being very similar to the Fruit Wax treatment in all attributes. It was also superior to Control and Film forming of Cassava Starch with respect to loss of fresh mass. Keywords: peach; postharvest; wax; cassava starch; storage.

\section{1 - INTRODUÇÃO}

O pessegueiro (Prunus persica L. Bastsch) é uma planta da família das rosáceas, originaria da Ásia. Dos frutos de clima temperado, o pêssego é um dos mais perecíveis, em razão do seu rápido metabolismo após a colheita. A aplicação de ceras começou a ser estudada na década de 80. Apesar de se mostrar eficiente, tem como principal limitação seu custo e o possivel efeito residual nos frutos. O uso da cobertura de cera para pêssegos estende-lhes a vida de mercado pela redução na perda de umidade e, conseqüentemente, do enrugamento, o que proporciona melhoria na aparência geral [4].

HAGENMAIER \& BAKER [9] afirmaram que as emulsões à base de cera de carnaúba dão melhor pro-

Recebido para publicação em 23/05/2001. Aceito para publicação em 07/07/2003 (000659).

${ }^{2}$ Centro de Raizes e Amidos Tropicais (CERAT/UNESP) - C.P. 237 - CEP 18603-970 -tel: 6821-9050 - Botucatu,SP e-mail: maoliveira2002@bol.com.br ${ }^{3}$ Centro de Raizes e Amidos Tropicais (CERAT/UNESP) - C.P. 237 - CEP 18603-970 - tel: 68219050 - Botucatu, SP

* A quem a correspondência deve ser enviada. teção contra a perda de massa fresca do que as ceras com base na goma laca, polietileno oxidado, ou resina de madeira. Conseqüentemente observaram melhor resistência à permeabilidade ao vapor d'água pelas emulsões de cera de carnaúba. Formulações contendo $5 \%$ de cera de carnaúba diminuem de $10 \%$ a $30 \%$ o amolecimento de goiabas [13].

Formulações de filmes comestiveis devem incluir pelo menos um componente capaz de formar uma matriz adequada, continua e coesa. Os materiais básicos para a constituição das formulações podem ser classificados em três categorias: polissacarideos, lipídeos e proteinas. Polissacarideos (gomas vegetais ou microbianas, amidos, celuloses, etc) apresentam boas propriedades para a formação de filmes. Filmes formados com estes componentes hidrofilicos proporcionam eficientes barreiras contra óleos e lipídios [15], mas suas propriedades como barreira para umidade são pobres.

KLUGE et al. [12] estudaram o efeito do Tal-prolong em frutos de pessegueiro da cultivar "BR-6" tratados nas concentrações $0 \% ; 0,5 \% ; 1,0 \% ; 1,5 \%$ e $2,0 \%$. Os frutos foram armazenados por 20 e 30 dias a $0^{\circ} \mathrm{C}$ e $90-95 \%$ de 
UR, antes de serem submetidos a um periodo de comercialização simulada de 2 dias $\left(25-26^{\circ} \mathrm{C}\right.$ e $\left.60-70 \% \mathrm{UR}\right)$. A aplicação de ésteres de sacarose, antes do armazenamento refrigerado, evitou perdas elevadas de acidez, em todas as concentrações. Entretanto, em relação às perdas de massa fresca pelos frutos, não se constatou efeito de ésteres de sacarose em relação aos frutos não tratados.

Biofilmes tendo o amido como biopolimero para sua formação, começam a ser estudados de forma mais intensiva, sendo a fécula de mandioca selecionada como sendo a matéria-prima mais adequada [3].

CEREDA, BERTOLINI \& EVANGELISTA [3] relataram o uso de película de amido de milho e de fécula de mandioca a $2 \%$ (massa fresca/volume de água), em substituição à cera comercial Mobilcer da Mobil Óleo do Brasil, para a aplicação como tratamento pós-colheita em frutos de mamão sob condições de ambiente. Os resultados mostraram que as utilizações do amido e da fécula não ocasionaram efeitos nocivos quando comparados ao tratamento com cera, além de serem efetivos na redução da perda de massa fresca pelos frutos.

OLIVEIRA [16] relatou que em frutos de goiaba armazenados à temperatura ambiente, a aplicação de películas de fécula de mandioca a 3\% e 5\% impediu a maturação dos mesmos, acarretando-lhes distúrbios fisiológicos. Em um segundo experimento, não foi constatado esta influência negativa à textura, coloração e teores de vitamina $\mathrm{C}$, com a utilização de menores concentrações, $1 \%$ e $2 \%$. VICENTINI, CEREDA \& CÂMARA [18] trabalhando com frutos de pimentão cv. 'Magali' recobertos com películas de fécula de mandioca a $1 \%$ e $3 \%$ e armazenados à temperatura ambiente, observaram que os frutos revestidos com estas peliculas apresentaram perda de massa fresca igual à da testemunha.

OLIVEIRA [16] verificou através de estudos que a película de fécula de mandioca proporcionava ótimo brilho aos frutos tratados, mas o atributo limitante ainda continuava a ser a perda de massa fresca.

Os hidrocolóides conferem melhores propriedades mecânicas para os filmes comestiveis do que os lipídios e as substâncias hidrofóbicas. Por essa razão, existe vantagem de se poder usar ambas as substâncias nos filmes comestiveis [7].

Jarvis et al. apud HAGENMAIER \& BAKER [9] afirmaram que os ácidos graxos de cadeia curta ou ácidos graxos insaturados reduzem a transpiração, mais que os ácidos graxos de cadeia longa e saturados.

Os processos de produção das formulações de filmes geralmente incluem um primeiro passo de solubilização das macromoléculas num agente solvente (freqüentemente água, etanol ou ácido acético), o qual pode conter aditivo (plasticizantes, agente de ligação, solutos, etc). Esta formulação é aplicada para a formação de uma fina camada envoltória, que usualmente é seguida por um tratamento de secagem[5].

HAGENMAIER \& BAKER [9] tentaram a substituição da morfolina por $\mathrm{KOH}$ na formulação das microemulsões, mas verificaram que os revestimentos tornaram-se inaceitáveis, pois não proporcionavam aos frutos uma boa redução na perda de massa fresca, durante o armazenamento.

CUQ, GONTARD \& GUILBERT [5] relataram que a adição de cera de abelha às películas formadas a partir de proteina de trigo, levou a redução na permeabilidade a vapor de água pela película, que passou de 69,7 x $10^{12}$ $\mathrm{mol} \cdot \mathrm{mm}^{-2} \cdot \mathrm{s}^{-1} \cdot \mathrm{Pa}^{-1}$ para 0,0230 x $10^{12} \mathrm{~mol} \cdot \mathrm{mm}^{-2} \cdot \mathrm{s}^{-1} \cdot \mathrm{Pa}^{-1}$.

BURNS \& ECHEVERRIA [2] armazenaram laranjas 'Hamlin' tratadas ou não com cera, por 8 semanas a $15,5^{\circ} \mathrm{C}$, e observaram que o suco dos frutos tratados com ceras, depois do periodo de armazenamento, apresentaram menores teores de sólidos solúveis totais.

OLIVEIRA [16] trabalhou com armazenamento de goiabas 'Kumagai' brancas, sob condições de ambiente, e verificou que a utilização da cera "Sta-Fresh" ocasionou uma diminuição nos teores de sólidos solúveis totais e açúcares redutores dos frutos.

MEREDITH, ROBERTSON \& HORUAT [14] relataram decréscimo na textura com o decorrer do amadurecimento. Afirmam que valores de 13 Newtons (3 libras.in ${ }^{-2}$ ) ou menores, são considerados aceitáveis para o consumo in natura. Pêssegos colhidos muito precocemente (imaturos) não desenvolveram textura aceitável para o consumo.

DAREZZO [6] armazenou pêssegos 'Biuti' sob condições de ambiente $\left(25,8^{\circ} \mathrm{C}\right.$ e $64 \%$ UR, em média), e sem acondicionamento durante 6 dias e verificou perda de massa fresca da ordem de $15,57 \%$ e relatou que os valores de textura decresceram ao longo do período. A variação foi de $26,86 \mathrm{~kg} . \mathrm{cm}^{-2}$ para $11,07 \mathrm{~kg} . \mathrm{cm}^{-2}$.

TEIXEIRA [17] relata que os constituintes químicos dos frutos de pessegueiro apresentam grande variação nos seus teores. Sólidos solúveis variam de 8,5 a $15,9 \%$, acidez titulável de 0,36 a 0,65 \% de ácido cítrico e pH de 3,2 a 4,7 .

MEREDITH, ROBERTSON \& HORUAT [14] estudaram o comportamento de frutos de pessegueiro colhidos em 6 estádios de maturação, e afirmaram que os niveis de ácidos orgânicos diminuem durante o armazenamento ( 7 dias a $21^{\circ} \mathrm{C}$ e $85 \%$ UR), desde que os frutos não sejam colhidos precocemente (abaixo do estádio 3). Com a maturidade, a concentração de ácido cítrico diminuiu, a de ácido málico aumentou e a do ácido succínico não apresentou diferenças significativas. A acidez total diminuiu com a progressão do amadurecimento.

Em pêssegos, os ácidos orgânicos identificados são o succínico, o málico e o cítrico. No período da colheita predominam os dois últimos. A acidez diminui com a maturação, com conseqüente aumento nos valores de $\mathrm{pH}[4]$.

Os pêssegos, como os demais órgãos vivos, apresentam intensidade respiratória intimamente dependente da temperatura, com o amadurecimento satisfatório a temperaturas entre $18^{\circ} \mathrm{C}$ e $29^{\circ} \mathrm{C}$. Com base na atividade respiratória, um dia a $21^{\circ} \mathrm{C}$ equivale, em 
termos de vida-útil do pêssego, a $2,4,8,16$ dias, a $15^{\circ} \mathrm{C}, 10^{\circ} \mathrm{C}, 5^{\circ} \mathrm{C}$ e $0^{\circ} \mathrm{C}$, respectivamente. A taxa respiratória de pêssegos é de $5,8,38$ e $72 \mathrm{mg}$ de $\mathrm{CO}_{2} \cdot \mathrm{kg}^{-1} \cdot \mathrm{h}^{-1}$ a $0^{\circ} \mathrm{C} ; 4,4^{\circ} \mathrm{C} ; 5,6^{\circ} \mathrm{C}$ e $21,1^{\circ} \mathrm{C}$, respectivamente [10].

Em pêssegos 'Hakuho', armazenados à $25^{\circ} \mathrm{C}$ e 65 $75 \%$ UR, a taxa respiratória aumentou progressivamente até o 12 - dia de armazenamento, atingindo valores de $65 \mathrm{ml}$ de $\mathrm{CO}_{2} \cdot \mathrm{kg}^{-1} \cdot \mathrm{h}^{-1}$ [8]. Sendo a densidade dos gases igual ao seu peso molar dividido por 22,4 , o valor de $65 \mathrm{~mL}$ de $\mathrm{CO}_{2} \cdot \mathrm{kg}^{-1} \cdot \mathrm{h}^{-1}$ equivale à $127 \mathrm{mg}$ de $\mathrm{CO}_{2} \cdot \mathrm{kg}^{-1} \cdot \mathrm{h}^{-1}$.

Com o intuito de estabelecer as condições necessárias para prolongar a pós-colheita de pêssegos, armazenados sob condições de ambiente, planejou-se o presente trabalho, com o objetivo de comparar o efeito da aplicação de uma microemulsão com base em fécula de mandioca e cera de abelha, com o da cera comercial ("Fruit wax") e o da película de fécula de mandioca na composição físico-química dos frutos durante o armazenamento.

\section{2 - MATERIAL E MÉTODOS}

Os frutos procederam de pomar comercial localizado no municipio de Botucatu, SP a $22^{\circ} 52^{\prime} 20^{\prime \prime}$ de Latitude Sul e 48 26' $37^{\prime \prime}$ de Longitude Oeste, com 800 metros de altitude, no municipio de Botucatu, SP. Foram colhidos manualmente, dia 12 de janeiro de 1999, e transportados em caixas de papelão, para o Departamento de Horticultura da F.C.A./UNESP/Botucatu onde foram realizados os experimentos. A variedade de pêssego utilizada foi a 'Biuti', que é "de mesa" e tardia.

Todos os frutos foram imersos em suspensão aquosa aquecida $\left(52^{\circ} \mathrm{C}\right)$ contendo $0,3 g . \mathrm{L}^{-1}$ (Benomyl), durante 2 minutos. Posteriormente estes frutos foram divididos em 4 tratamentos: Testemunha, "Fruit Wax", Fécula e Microemulsão. Os frutos que constituíram o tratamento testemunha foram colocados diretamente em caixas de pêssegos/papelão ondulado, de dimensões internas $480 \mathrm{~mm}$ X $300 \mathrm{~mm}$ X 100mm, enquanto os demais foram divididos em 3 grupos para receberem os tratamentos e posteriormente serem colocados em caixas de papelão para acompanhamento dos tratamentos.

A formulação de Fécula foi obtida através da suspensão de 40 gramas em água, e o volume completado para 2 litros, com aquecimento até $70^{\circ} \mathrm{C}$ e com agitação constante até o ponto de geleificação. A seguir, a suspensão foi deixada em repouso até o resfriamento sob condições de ambiente.

A formulação da Microemulsão de fécula com cera de abelha foi obtida através da mistura de 20 gramas fécula de mandioca; 40 gramas de cera de abelha; 20 gramas de glicerol; 2,5 gramas de $\mathrm{KOH}$ e $5 \mathrm{~mL}$ de éter etilico como antiespumante, em um becker de 2 litros acrescido de um volume de água de $500 \mathrm{~mL}$. Aqueceu-se a mistura durante 30 minutos. Em seguida, após o esfriamento, adicionou-se água até o volume de 1 litro, filtrou-se em peneira doméstica.

Os frutos tratados com "Fruit Wax", Fécula e Microemulsão após a imersão rápida foram colocados para secar, em bancada, sob condições de ambiente antes do acondicionamento.

No armazenamento foram registradas temperaturas médias de $27,2 \pm 3,0^{\circ} \mathrm{C}$ e umidade relativa média de $70 \pm 11 \%$, durante os 12 dias. Os frutos foram avaliados a cada 3 dias.

\section{1 - Análises físicas, físico-químicas e químicas}

Frutos de todos os tratamentos foram analisados quanto à perda de massa fresca e a taxa de respiração [16], formando o grupo não destrutivo. Para o grupo destrutivo foram feitas análises de textura (Texturômetro Stevens - LFRA Texture Analyser, com a ponta de prova - A 9/1000), sólidos solúveis totais [1], indice $\mathrm{pH}$ e acidez total titulável [11].

Para o grupo controle se determinou curvas de regressão de perda de massa fresca para cada tratamento. Para as análises destrutivas, o delineamento estatístico adotado foi o inteiramente casualizado, segundo um esquema fatorial 4 X 4 (4 tratamentos e 4 períodos de armazenamento. As médias foram comparadas ao nivel de $5 \%$ de probabilidade, pelo teste de Tukey.

O grupo controle foi composto por 6 frutos por tratamento totalizando 24 frutos. O grupo destrutivo foi composto por 6 frutos de cada tratamento (2 frutos por repetição) analisados aos 3, 6 , 9 e 12 dias de armazenamento totalizando 24 frutos por tratamento. Assim sendo no grupo destrutivo totalizou-se 96 frutos. O número total de frutos no experimento foi de 120 frutos.

\section{3 - RESULTADOS E DISCUSSÃo}

\section{1 - Perda de massa fresca}

Nas condições deste experimento os frutos dos tratamentos Testemunha, "Fruit Wax", Fécula e Microemulsão apresentaram perda de massa fresca da ordem de $10,61 \%, 8,92 \%, 11,52 \%$ e 9,38\%, respectivamente, após 6 dias de armazenamento sob condições de ambiente, dados semelhantes ao relatado por DAREZZO [6] que verificou perda de massa fresca da ordem de $15,57 \%$, para o tratamento Testemunha. Os tratamentos com a cera "Fruit Wax" e com a Microemulsão proporcionaram numericamente uma menor perda de massa fresca pelos frutos do que os tratamentos Testemunha e Fécula (Figura 1). Estes dados concordam cOm CHITARRA \& CARVALHO [4] e HAGENMAIER \& BAKER [9] que afirmaram que o uso da cobertura de cera em pêssegos estende-lhes a pós-colheita.

KLUGE et a1. [12] verificaram o efeito do "Talprolong" em frutos de pessegueiro e em relação às perdas de massa fresca, não houve efeito dos ésteres de sacarose em relação aos frutos não tratados. Este tratamento se assemelha muito ao tratamento com a Fécula que também é um polissacarídeo e não apresentou efeito de redução à perda de massa fresca pelos frutos. OLIVEIRA [16] e VICENTINI, CEREDA \& CÂMARA [18] também relataram a baixa eficiência da Fécula em prevenir a perda de massa fresca quando 
aplicada em goiaba e pimentão, entretanto CEREDA, BERTOLINI \& EVANGELISTA [3] trabalhando com mamão, obteve resultados satisfatórios. Estes dados concordam com MURRAY, MARDTTA \& BOETTGER [15] que afirmaram que os polissacarideos apresentam boas propriedades de formação de filmes, entretanto suas propriedades como barreira para a umidade são pobres.

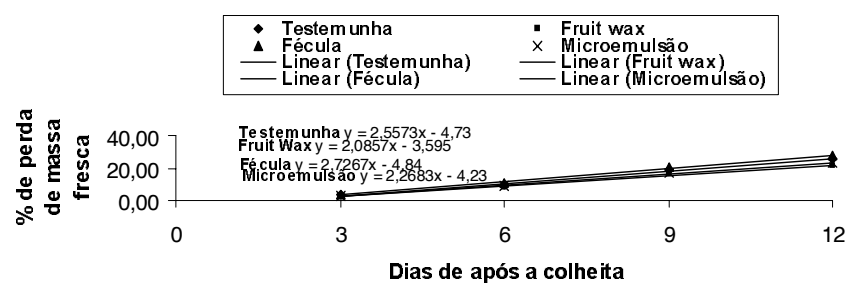

FIGURA 1. Curvas de regressão da perda de massa fresca de pêssegos 'Biuti', submetidos a diferentes tratamentos e armazenados sob condições de ambiente $\left(27,2 \pm 3{ }^{\circ} \mathrm{C}\right.$ e $70 \pm 11 \%$ UR).

HAGENMAIER \& BAKER [9] observaram que a utilização do KOH na formulação das microemulsões torna o revestimento inaceitável, devido a não proporcionarem aos frutos uma boa redução na perda de massa fresca. Estes dados discordam do experimento onde a formulação Microemulsão, que contém $\mathrm{KOH}$ em sua formulação, obteve efeito similar ao do tratamento à base de cera de carnaúba ("Fruit Wax") quanto a diminuição da perda de massa fresca pelos frutos.

Para emulsões de cera de carnaúba se observa uma melhor resistência à permeabilidade ao vapor d'água. A "Fruit Wax" é uma cera à base de carnaúba, aplicada sem diluição, o que proporcionou a menor perda de massa fresca obtida nos frutos avaliados, dados estes concordantes com MCGUIRE \& HALLMAN [13]. O tratamento com a Microemulsão não diferiu do tratamento com a cera "Fruit Wax", sendo comprovada a eficiência dos dois tratamentos em diminuir a perda de massa fresca pelos frutos durante o armazenamento.

Os hidrocolóides usualmente promovem melhores propriedades mecânicas para os filmes comestiveis do que os lipídios e substâncias hidrofóbicas. Por essa razão, existe vantagem ao usar ambas as substâncias na composição dos filmes comestiveis, hidrocoloides e lipídios [7]. O tratamento com a Microemulsão foi elaborado com este propósito, seguindo também relatos de CUQ, GONTARD \& GUILBERT [5] que afirmaram que a adição de cera de abelha levava a uma diminuição da permeabilidade ao vapor d'água.

A eficiência do tratamento com a Microemulsão foi devido aos ácidos graxos de cadeia curta e/ou ácidos graxos insaturados da cera de abelha com propriedade de reduzir a transpiração em concordância com os relatos de Jarvis et al. (1962), apud HAGENMAIER \& BAKER [9].

\section{2 - Curva de respiração}

O pêssego é um fruto climatérico, pois no final da maturação há um aumento marcante na evolução de
$\mathrm{CO}_{2}$. Neste experimento o pico climatérico foi de 39,44; 43,53; 48,69 e 40,61 mg de $\mathrm{CO}_{2} \cdot \mathrm{kg}^{-1} \cdot \mathrm{h}^{-1}$, respectivamente, para os tratamentos Testemunha, "Fruit Wax", Fécula e Microemulsão (Figura 2).

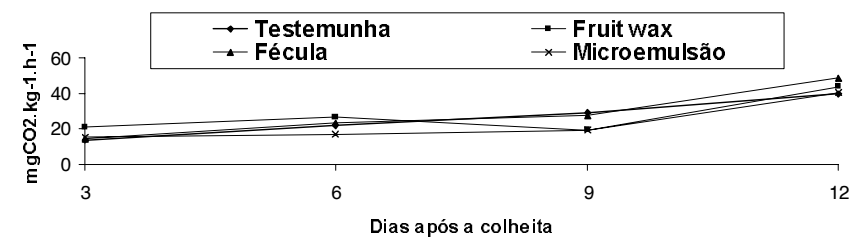

FIGURA 2. Comportamento respiratório de pêssegos 'Biuti', submetidos a diferentes tratamentos e armazenados sob condição ambiente $\left(27,2 \pm 3^{\circ} \mathrm{C}\right.$ e $70 \pm 11 \%$ UR).

Verificou-se que as taxas respiratórias foram numericamente muito semelhantes entre os tratamentos, portanto não houve interferência dos tratamentos na respiração.

Os dados de picos climatéricos deste experimento foram inferiores aos encontrados por HARDENBURGER [10] e DU, GEMMA \& IWAHORI [8] que armazenaram pêssegos a $21,1^{\circ} \mathrm{C}$ e $25^{\circ} \mathrm{C}$, respectivamente, encontrando valores de $72 \mathrm{mg}$ de $\mathrm{CO}_{2} \cdot \mathrm{kg}^{-1} \cdot \mathrm{h}^{-1}$ e $127 \mathrm{mg}$ de $\mathrm{CO}_{2} \cdot \mathrm{kg}^{-1} \cdot \mathrm{h}^{-1}$.

\section{3 - Textura}

Com o avanço da maturação durante o armazenamento e a chegada da senescência, espera-se um decréscimo nos valores de textura, pois apesar de ser um parâmetro físico, está estreitamente relacionado com a solubilização das substâncias pécticas que possuem o grupo carboxílico ligado ao cálcio (protopectina), sendo que frutos com elevada percentagem de pectina solúvel são amolecidos e pouco resistentes. Portanto, com o amadurecimento ocorre a solubilização de substâncias pécticas, isto é, a transformação de pectina insolúvel em pectina solúvel, com a liberação dos pectatos de cálcio e conseqüente amolecimento dos frutos. Observando-se os valores apresentados na Tabela 1, verificou-se este comportamento para todos os tratamentos durante o periodo de armazenamento. Estes dados encontram apoio em MEREDITH, ROBERTSON \& HORUAT [4] e DAREZZO [6] que verificaram que os valores de textura decresceram ao longo do período.

TABELA 1. Valores médios obtidos para a textura (gf) de pêssegos 'Biuti', a cada 3 dias, submetidos a diferentes tratamentos e armazenados sob condições de ambiente $\left(27,2 \pm 3^{\circ} \mathrm{C}\right.$ e $70 \pm 11 \%$ UR).

\begin{tabular}{l|c|c|c|c|c}
\hline & \multicolumn{5}{c}{ Dias de Armazenamento } \\
\hline Tratamentos & 3 & 6 & 9 & 12 & Mé dia \\
\hline Testemunha & 155 & 110 & 119 & 85 & $117 \mathrm{~A}$ \\
"Fruit Wax" & 164 & 113 & 123 & 77 & $119 \mathrm{~A}$ \\
Fécula & 167 & 136 & 148 & 60 & $128 \mathrm{~A}$ \\
Microemulsão & 127 & 112 & 130 & 57 & $106 \mathrm{~A}$ \\
Média & $153 \mathrm{a}$ & $118 \mathrm{~b}$ & $130 \mathrm{~b}$ & $70 \mathrm{c}$ & \\
\hline
\end{tabular}

médias de tratamentos seguidas de letras maiúsculas iguais não diferem significativamente $(p>0.05)$.

médias de épocas seguidas de letras minúsculas iguais não diferem significativamente $(p>0.05)$
c.v. $=22.79 \%$

Em relação aos tratamentos, não se verificou diferença significativa entre os mesmos (Tabela 1). Portan- 
to, a diminuição da perda de massa fresca relatada nos frutos dos tratamentos "Fruit Wax" e Microemulsão não foi suficiente para que ocorresse uma menor diminuição na textura dos frutos durante o armazenamento.

\section{4 - Sólidos solúveis totais (SST)}

Durante o armazenamento espera-se um aumento nos teores de SST devido ao amadurecimento dos frutos. Entretanto, isto não ocorreu no experimento sob condições de ambiente. Assim sendo, os teores de SST dos frutos não variaram significativamente durante o periodo de armazenamento, apresentando valores na faixa de $7,9^{\circ} \mathrm{Brix}$ a $10,1^{\circ} \mathrm{Brix}$, valores estes encontrados dentro da faixa de $8,5^{\circ} \mathrm{Brix}$ a $15,9^{\circ} \mathrm{Brix}$, relatada por TEIXEIRA [17] (Tabela 2).

TABELA 2. Teores médios obtidos para os sólidos solúveis totais ( ${ }^{\circ}$ Brix) de pêssegos 'Biuti', a cada 3 dias, submetidos a diferentes tratamentos e armazenados sob condições de ambiente $\left(27,2 \pm 3^{\circ} \mathrm{C}\right.$ e $70 \pm 11 \%$ UR).

\begin{tabular}{l|c|c|c|c|c}
\hline & \multicolumn{5}{|c}{ Dias de Armazenam ento } \\
\hline Tratament os & 3 & 6 & 9 & 12 & Média \\
\hline Testemunha & 9,3 & 9,2 & 10,1 & 9,0 & $9,4 \mathrm{~A}$ \\
"Fruit Wax" & 8,8 & 8,8 & 7,9 & 8,1 & $8,4 \mathrm{~B}$ \\
Fécula & 9,6 & 8,8 & 9,4 & 8,9 & $9,2 \mathrm{~A}$ \\
Microemulsão & 9,0 & 8,8 & 9,0 & 8,8 & $8,9 \mathrm{AB}$ \\
Média & $9,2 \mathrm{a}$ & $9,1 \mathrm{a}$ & $8,9 \mathrm{a}$ & $8,7 \mathrm{a}$ & \\
\hline
\end{tabular}

médias de tratamentos seguidas de letras maiúsculas iguais não diferem significatimédias de épocas seguidas de letras minúsculas iguais não diferem significativamente $(p>0,05)$
c.v. $=6,97 \%$

Em relação aos tratamentos, os frutos do tratamento com a cera "Fruit Wax" apresentaram teores inferiores de SST em relação aos frutos dos tratamentos Testemunha e Fécula. Os frutos do tratamento Microemulsão não diferiram significativamente de nenhum dos outros tratamentos. OLIVEIRA [16], quando trabalhou com armazenamento de goiabas, verificou que a utilização da cera "Sta-Fresh" ocasionou uma diminuição nos teores de SST dos frutos. BURNS \& ECHEVERRIA [2] armazenaram laranjas 'Hamlin' tratadas ou não com cera por 8 semanas a $15,5^{\circ} \mathrm{C}$ e observaram que o suco dos frutos tratados com ceras, depois do período de armazenamento, obtiveram menores teores de SST. Portanto, os menores teores encontrados para os frutos submetidos ao tratamento "Fruit Wax" são concordantes com os dos trabalhos acima.

\section{5 - Acidez total titulável (ATT)}

A maturação levou a uma diminuição nos valores de acidez total titulável durante o período de armazenamento para os tratamentos "Fruit Wax", Fécula e Microemulsão. Estes dados são concordantes com os de CHITARRA \& CARVALHO [4] e MEREDITH, ROBERTSON \& HORUAT [14]. Apenas o tratamento Testemunha não apresentou diminuição nos valores de acidez durante o armazenamento, pois ocorreu um pico de acidez no $12^{\circ}$ dia de armazenamento, devido ao avançado estádio de senescência dos frutos deste tratamento (Tabela 3).
TEXEIRA [17] afirmou que a acidez total titulável em pêssegos expressa em \% de ácido cítrico varia de 0,36 a 0,65. Neste experimento a variação foi de 0,50 a $0,78 \%$, ou seja, os frutos do experimento possuiam uma acidez mais elevada do que as relatadas pelos autores.

TABELA 3. Valores médios obtidos para a acidez total titulável (\% de ácido cítrico) de pêssegos 'Biuti', a cada 3 dias, submetidos a diferentes tratamentos e armazenados sob condições de ambiente $\left(27,2 \pm 3^{\circ} \mathrm{C}\right.$ e $70 \pm 11 \%$ UR).

\begin{tabular}{l|c|c|c|c|c}
\hline & \multicolumn{5}{|c}{ Dias de Armazenamento } \\
\hline Tratamentos & \multicolumn{1}{|c}{3} & \multicolumn{1}{c}{6} & \multicolumn{1}{c}{9} & \multicolumn{1}{c}{12} & Média \\
\hline Testemunha & $0,76 \mathrm{Aa}$ & $0,76 \mathrm{Aa}$ & $0,64 \mathrm{Aa}$ & $0,79 \mathrm{Aa}$ & 0,74 \\
"Fruit Wax" & $0,77 \mathrm{Aa}$ & $0,66 \mathrm{Aab}$ & $0,51 \mathrm{Bb}$ & $0,52 \mathrm{Bb}$ & 0,61 \\
Fécula & $0,78 \mathrm{Aa}$ & $0,71 \mathrm{Aab}$ & $0,63 \mathrm{Aab}$ & $0,56 \mathrm{Bb}$ & 0,67 \\
Microemulsão & $0,75 \mathrm{Aa}$ & $0,64 \mathrm{Aab}$ & $0,57 \mathrm{Ab}$ & $0,50 \mathrm{Bb}$ & 0,62 \\
Média & 0,76 & 0,69 & 0,59 & 0,59 & \\
\hline
\end{tabular}

médias de tratamentos seguidas de letras maiúsculas iguais não diferem significativamente $(p>0,05)$.

médias de épocas seguidas de letras minúsculas iguais não diferem significativamente $(p>0,05)$

\section{6 - Índice $\mathbf{p H}$}

Com a maturação ocorreu aumento nos valores de $\mathrm{pH}$, verificado a partir do 6o dia de armazenamento, devido a uma conseqüente diminuição nos valores de acidez total titulável (Tabela 4). Estes dados são concordantes com CHITARRA \& CARVALHO [4].

TABELA 4. Valores médios obtidos para o Índice de $\mathrm{pH}$ de pêssegos 'Biuti', a cada 3 dias, submetidos a diferentes tratamentos e armazenados sob condições de ambiente $\left(27,2 \pm 3^{\circ} \mathrm{C}\right.$ e $70 \pm 11 \%$ UR).

\begin{tabular}{l|c|c|c|c|c}
\hline & \multicolumn{5}{|c}{ Dias de Armazenamento } \\
\hline Tratamentos & 3 & 6 & 9 & 12 & Média \\
\hline Testemunha & 3,0 & 2,8 & 2,9 & 3,0 & $2,9 \mathrm{~B}$ \\
"Fruit Wax" & 3,0 & 3,0 & 3,2 & 3,4 & $3,1 \mathrm{~A}$ \\
Fécula & 3,0 & 2,9 & 3,1 & 3,4 & $3,1 \mathrm{~A}$ \\
Microemulsão & 3,1 & 3,0 & 3,1 & 3,5 & $3,2 \mathrm{~A}$ \\
Média & $3,0 \mathrm{bc}$ & $2,9 \mathrm{c}$ & $3,1 \mathrm{~b}$ & $3,3 \mathrm{a}$ & \\
\hline
\end{tabular}

médias de tratamentos seguidas de letras maiúsculas iguais não diferem significativamente $(p>0,05)$.

médias de épocas seguidas de letras minúsculas iguais não diferem significativamente $(p>0,05)$
.

TEIXEIRA [17] afirma que o $\mathrm{pH}$ em pêssegos, varia de 3,2 a 4,7. Neste experimento os valores variaram de 2,8 a 3,5; portanto os frutos analisados possuiam indices mais baixos dos que os relatados por este autor. Assim sendo, os valores deste experimento estão próximos ao limite inferior.

Verificou-se que os frutos do tratamento Testemunha obtiveram indices de $\mathrm{pH}$ mais baixos do que os frutos dos demais tratamentos, principalmente no 9o e 12 o dia de armazenamento (Tabela 4). Isto era esperado devido ao fato dos frutos do tratamento Testemunha apresentarem valores de acidez mais elevados no 12 ㅇa de armazenamento.

\section{4 - CONCLUSÕES}

Para as condições de realização dos experimentos, pode-se concluir que: 
- A utilização da formulação Microemulsão superou as expectativas, por equivaler ao tratamento "Fruit Wax" em todas as análises físico-químicas dos frutos. Testemunha e Fécula foram semelhantes em todos os atributos. O atributo marcante foi a perda de massa fresca, onde os tratamentos com a cera "Fruit Wax" e com a Microemulsão proporcionaram uma menor perda de água pelos frutos do que os tratamentos Testemunha e Fécula.

\section{5 - REFERÊNCIAS BIBLIOGRÁFICAS}

[1] ASSOCIATION OF OFFICIAL ANALYTICAL CHEMISTS. Official methods as analysis of the association of official analytical chemists. 11.ed. Washington, 1970. 1015p.

[2] BURNS, J.K.; ECHEVERRIA, E. Assessment of quality loss during commercial harvesting and postharvest handling of 'Hamlin' oranges. Proceedings of Florida State Horticultural Society, v.101, p.76-9, 1988.

[3] Cereda, M. P., Bertolini, A. C., EVAngelista, R. M. Uso do amido em substituição às ceras na elaboração de "filmes" na conservação pós-colheita de frutas e hortaliças: Estabelecimento de curvas de secagem. In: CONGRESSO BRASILEIRO DE MANDIOCA, 7, 1992, Recife. Resumos... Recife: Sociedade Brasileira de Mandioca, 1992. p.107.

[4] CHITARRA, M.I.F.; CARVALHO, V.D. Frutos temperados: pêssegos, ameixas e figos. Informe Agropecuário, v.11, n.125, p.56-66, 1985.

[5] CUQ, B.; GONTARD, N.; GUILBERT, S. Edible films and coatings as active layers. In: ROONEY, M. Active food packaging. Blackie Academic and Profissional, 1995. p. 111-42.

[6] DAREZZO, H. M. Conservação pós-colheita de pêssegos 'Aurora' e 'Biuti' acondicionados em diferentes embalagens e armazenados sob condições de ambiente e refrigeração. Jaboticabal, 1998, 129p. Dissertação (Mestrado em Agronomia - Produção Vegetal) - Faculdade de Ciências Agrárias e Veterinária, Universidade Estadual Paulista. (UNESP).

[7] DEBEAUFORT, F.; VOILley, A. Aroma compound and water vapor permeability of edible films and polymeric packaging. J. Agri. Food Chem., v.42, n.12, p.2871, 1994.
[8] DU, J.; GEMMA, H.; IWAHORI, S. Effects of chitosan on the storage of peach, pear and kiwifruit. J. Japan Soc. Hort. Sci., v.66, n.1, p.15-22, 1997.

[9] HAGENMAIER, R.D.; BAKER, R.A. Wax microemulsions and emulsions as citrus coating. J. Agric. Food Chem., v.42, p. 899-902, 1994.

[10] HARDENBURG, R.E. Effect of in-package environment on keeping quality of fruits and vegetables. Hortscience, v.6, n.3, p.198-202, 1971.

[11] INSTITUTO ADOLFO LUTZ. Normas Analíticas: métodos químicos e físico-químicos para análise de alimentos. $3^{\text {a }}$ ed, São Paulo, 1985, v.1, 533p.

[12] KLUGE, R.A.; NACHTIGAL, J.C.; HOFFMANN, A.; BILHALVA, A.B.; FACHINELO, J.C. Efeito de ésteres de sacarose sobre pêssegos 'BR-6' refrigerados. Pesquisa Agropecuária Brasileira, v.33, n.2, p.109-14, 1998.

[13] McGUIRE R.G.; HALlMAN, G.J. Coating guavas with cellulose- or carnauba-based emulsions interferes with postharvest ripening. Postharvest Biology e Technology, v.30, n.2, p.294-5, 1995.

[14] MEREDITH, F.I.; ROBERTSON, J.A.; HORVAT, R.J. Changes in physical and chemical parameters associated with quality and postharvest ripening of harvester peaches. Journal of Agriculture and Food Chemistry, v.37, p.1210-14, 1989.

[15] MURRAY, D.G.; MARDTTA, N.G.; BOETTGER, R.M. Amylose coating for deep fried potatoes. US Patent Reissue, v.27, p.537, 1972.

[16] OLIVEIRA, M. A. de. Utilização de películas de fécula de mandioca como alternativa à cera comercial na conservação pós-colheita de frutos de goiaba (Psidium guayava) variedade Kumagai. Piracicaba, 1996, 73p. Dissertação (Mestrado em Ciência e Tecnologia de Alimentos) - Escola Superior de Agricultura "Luiz de Queiróz", Universidade de São Paulo. (USP)

[17] TEIXEIRA, M.C.R. Parâmetros físicos e químicos de dez variedades de pessegueiros. Lavras, 1979. 142p. Dissertação (Mestrado em Ciência dos Alimentos) - Escola Superior de Agronomia de Lavras. (ESAL).

[18] Vicentini, N. M., CEREDA, M. P., CÂMARA, F. L. A. Utilização de película de fécula de mandioca para conservação pós-colheita de frutos de pimentão (Capsicum annum L.) In: CONGRESSO LATINO AMERICANO DE RAIIZES TROPICAIS, 1, e CONGRESSO BRASILEIRO DE MANDIOCA, 9, 1996, São Pedro-SP. Resumos... Botucatu: Centro de Raizes Tropicias, Universidade Estadual Paulista, 1996. n. 138. 